\title{
CHANGES IN CEREBROSPINAL FLUID PRESSURE UNDER THE INFLUENCE OF CONTINUOUS SUBARACHNOIDAL INFUSION OF NORMAL SALINE
}

\author{
By FRANCIS F. FOLDES ẠNd JULIA G. ARROWOOD \\ (From the Department of Anesthesia, Massachusetts General Hospital, and the Anesthesia \\ Laboratory, Harvard Medical School, at the Massachusetts General Hospital, Boston)
}

(Received for publication January 16, 1948)

In 1944 we described a method (1) for the production of analgesia by the continuous subarachnoid infusion of dilute solution of local anesthetic agents (procaine $0.5 \%$ ). The method involved the introduction into the subarachnoid space of larger volumes of fluids than those used in earlier methods. Manometric measurements of the spinal fluid pressure in the course of the first few anesthesias administered by the new method showed that at the rate of infusion employed (4 to 10 drops per minute) the spinal fluid pressure was elevated only moderately, and the elevation caused no symptoms (2). Nevertheless it seemed that it would be of interest to study the effect of subarachnoidal infusion on a group of non-anesthetized patients; to observe the changes of the spinal fluid pressure with different rates of infusion and find out what, if any, symptoms accompany a sustained pressure.

\section{MATERIAL AND METHOD}

This study was carried out in 15 male and five female patients from the Neurosurgical Service of the Massachusetts General Hospital. The ages ranged between 16 and 70 years. All patients needed lumbar puncture for diagnostic purposes. Patients whose findings indicated disturbed cerebrospinal fluid dynamics were excluded from the study.

The selected patients received $0.2 \mathrm{gm}$. of phenobarbital by mouth one and one-half hours before the start of the experiment. Lumbar puncture was accomplished and the spinal needle connected to the apparatus for continuous subarachnoid infusion in the manner described in previous communications $(1,2)$ (Figure 1 ).

The patient was then placed in the supine position and initial levels of spinal fluid pressure, pulse rate and blood pressure were taken and recorded. The spinal fluid pressures measured with this setup were somewhat higher than those usually obtained with the patient in the lateral horizontal position. This was due to the fact that the zero point of the manometer was adjusted to the level of the skin of the back, and that the head was somewhat elevated by the small pillow. Since we were more interested in changes of the spinal fluid pressure than in absolute value this arrangement was selected, because it offered greater comfort to the patient and uniform conditions of observation. Resting level of the spinal fluid pressure was determined by repeated readings, and spinal fluid dynamics were tested by observing the effect of jugular compression on spinal fluid pressure. Normal saline and Hartman solution were used alternately for the subarachnoid infusion. No difference could be observed between the two fluids in their effect on spinal fluid pressure changes. The specific gravity of the spinal fluid and the infused saline was not considered in the pressure measurements.

Fluid was administered intrathecally at the rate of 4 , $8,12,16$ and 60 drops per minute to four persons in each

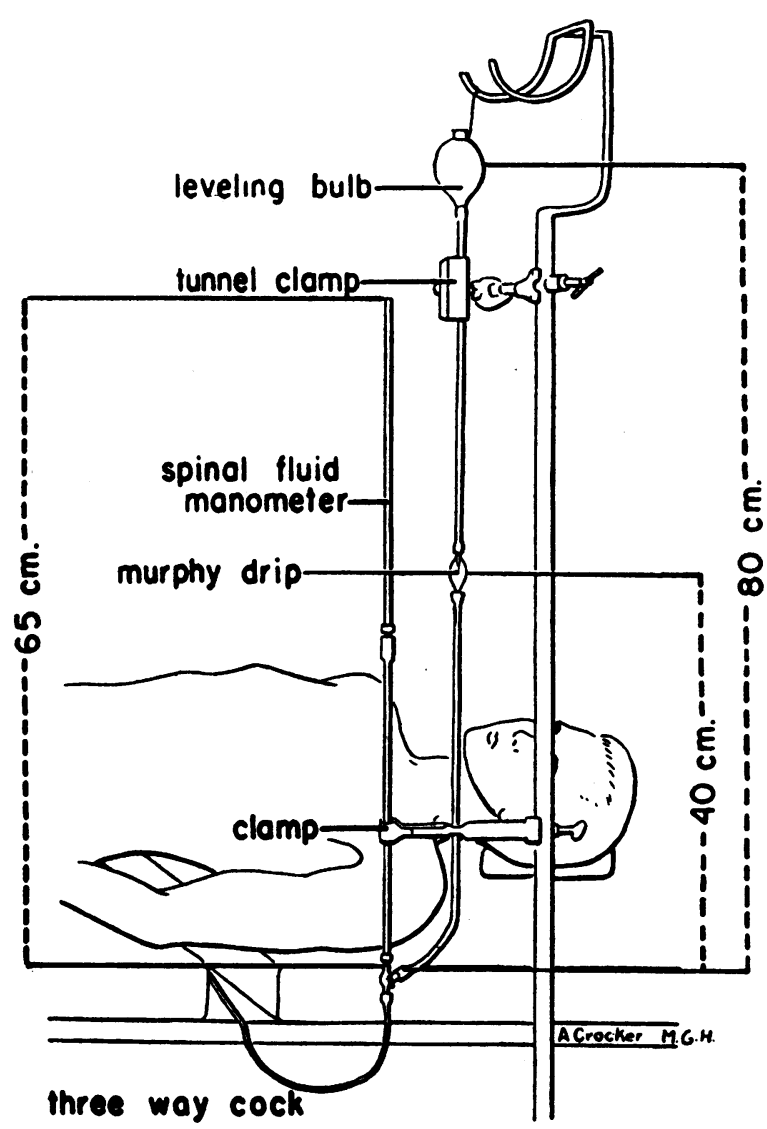

Fig. 1. Diagram of the Apparatus Used 
TABLE I

The relationship between the rates of infusion and the approximate manometric pressure, measured under conditions similar to those in the subarachnoidal space

Rate of drops per min.

Pressure in mm. $\mathrm{H}_{2} \mathrm{O}$
270
330
380
390
590

group. The dripper used delivered 20 drops to one cc. When the rate was between 4 and 16 drops per minute the subarachnoid infusion was continued for 60 minutes. At the end of this period the rate was increased for a varying length of time (10 to 20 minutes) to $30-80$ drops per minute. When the starting rate was 60 drops per minute the infusion was continued for 20 minutes. Spinal fluid pressure, pulse rate, and blood pressure were recorded every 10 minutes and in some of the earlier experiments neurological signs and symptoms were also observed. ${ }^{1}$ The patients were instructed to report any changes in their sensations. These were also recorded. After the infusion was discontinued, spinal fluid pressure was observed every minute until it became more or less stabilized. If this level was considerably higher than the initial spinal fluid pressure of the patient, spinal fluid was removed at the rate of $2 \mathrm{cc}$. per minute until normal or slightly higher than normal pressure was obtained. The spontaneous remission of the spinal fluid pressure of the four persons, in whom the initial rate of infusion was 60 drops per minute, was observed for 30 minutes. In these patients, spinal fluid pressure readings were made every minute in the first five minutes and every five minutes thereafter for 25 minutes.

Besides the quantity of the fluid administered it also seemed necessary to know the pressure under which the fluid entered the subarachnoid space. Because of the complexity of the physical factors involved, this pressure could not be calculated readily and had to be determined experimentally. An approximate measure of the pressures involved could be obtained by placing the Hingson needle at the end of the assembled apparatus in a glass tube closed at one end, containing normal saline solution. The level of the saline in the tube was regulated so that the hydrostatic pressure within it was the same as the average spinal fluid pressure at which a dynamic equilibrium developed between the quantity of the fluid administered and the quantity absorbed by the cerebrospinal system. Naturally this pressure varied with the different rates of infusion. Table I presents the manometric pressures of the system obtained at the different rates of infusion under the experimental conditions described.

\section{RESULTS}

The spinal fluid pressures of all the experimental subjects before the start of the infusion,

$1 \mathrm{We}$ wish to express our gratitude to Dr. J. J. Michelsen who made the neurological observations in some of our experiments. and every 10 minutes thereafter for 60 minutes, are presented in Table II. Figure 2 presents the combined spinal fluid pressure curves obtained at different rates of infusion. The first four curves show similar features. All four indicate a steady rise of pressure for 40 minutes, and all four curves become more or less parallel with the $\mathrm{X}$ axis, indicating that development of equilibrium occurs between the quantity of the fluid administered, and amount absorbed by the cerebrospinal system. The equilibrium was reached at progressively higher levels as the rate of administration was increased, but the increase of the equilibrium pressure did not increase in straight proportion with the rate of administration. Equilibrium was reached with the infusion rate of 4 drops per minute at $265 \mathrm{~mm}$. of $\mathrm{H}_{2} \mathrm{O}$ pressure, with 8 drops per minute of $330 \mathrm{~mm}$. pressure, with 12 drops per

TABLE II

Spinal fluid pressures before and after the subarachnoidal infusion of normal saline at various rates

\begin{tabular}{|c|c|c|c|c|c|c|c|c|c|c|}
\hline \multirow{2}{*}{$\begin{array}{c}\text { Drops/ } \\
\text { min. }\end{array}$} & \multicolumn{3}{|c|}{ Patient } & \multicolumn{7}{|c|}{ Pressure in $\mathrm{mm} . \mathrm{H}_{2} \mathrm{O}$} \\
\hline & Name & Sex & Age & $\begin{array}{c}\text { Before } \\
\text { infu- } \\
\text { sion }\end{array}$ & $10^{\prime}$ & $20^{\prime}$ & $30^{\prime}$ & $40^{\prime}$ & $50^{\prime}$ & $60^{\prime}$ \\
\hline \multirow[t]{2}{*}{4} & $\begin{array}{l}\text { J. D. } \\
\text { M. M. } \\
\text { A.S. } \\
\text { J.S. }\end{array}$ & & $\begin{array}{l}56 \\
69 \\
57 \\
46\end{array}$ & $\begin{array}{l}210 \\
210 \\
250 \\
250\end{array}$ & $\begin{array}{l}200 \\
240 \\
255 \\
240\end{array}$ & $\begin{array}{l}230 \\
240 \\
260 \\
250\end{array}$ & $\begin{array}{l}230 \\
240 \\
270 \\
300\end{array}$ & $\begin{array}{l}240 \\
275 \\
290 \\
-\end{array}$ & $\begin{array}{l}270 \\
250 \\
280 \\
-\end{array}$ & $\begin{array}{l}270 \\
240 \\
280 \\
-\end{array}$ \\
\hline & \multicolumn{3}{|c|}{ Average } & 230 & 234 & 245 & 260 & 268 & 266 & 263 \\
\hline \multirow[t]{2}{*}{8} & $\begin{array}{l}\text { K. D. } \\
\text { E. G. } \\
\text { H. M. } \\
\text { R. B. }\end{array}$ & & $\begin{array}{l}70 \\
51 \\
57 \\
16\end{array}$ & $\begin{array}{l}190 \\
230 \\
240 \\
250\end{array}$ & $\begin{array}{l}185 \\
250 \\
265 \\
280\end{array}$ & $\begin{array}{l}340 \\
270 \\
260 \\
250\end{array}$ & $\begin{array}{l}340 \\
300 \\
280 \\
280\end{array}$ & \begin{tabular}{|l|}
380 \\
330 \\
300 \\
270
\end{tabular} & $\begin{array}{l}380 \\
330 \\
330 \\
290\end{array}$ & $\begin{array}{l}370 \\
330 \\
320 \\
300\end{array}$ \\
\hline & \multicolumn{3}{|c|}{ Average } & 230 & 245 & 280 & 300 & 320 & 330 & 330 \\
\hline \multirow[t]{2}{*}{12} & $\begin{array}{l}\text { A. H. } \\
\text { A. M. } \\
\text { F. T. } \\
\text { F. C. }\end{array}$ & & $\begin{array}{l}38 \\
54 \\
70 \\
59\end{array}$ & $\begin{array}{l}180 \\
180 \\
200 \\
230\end{array}$ & $\begin{array}{l}200 \\
200 \\
230 \\
300\end{array}$ & $\begin{array}{l}230 \\
240 \\
260 \\
390\end{array}$ & $\begin{array}{l}280 \\
300 \\
310 \\
430\end{array}$ & $\begin{array}{l}320 \\
320 \\
350 \\
430\end{array}$ & $\begin{array}{l}320 \\
350 \\
340 \\
430\end{array}$ & $\begin{array}{l}340 \\
340 \\
320 \\
430\end{array}$ \\
\hline & \multicolumn{3}{|c|}{ Average } & 197 & 230 & 280 & 320 & 355 & 360 & 357 \\
\hline \multirow[t]{2}{*}{16} & $\begin{array}{l}\text { L. M. } \\
\text { I. F. } \\
\text { N. L. } \\
\text { H. K. }\end{array}$ & & $\begin{array}{l}69 \\
48 \\
58 \\
52\end{array}$ & $\begin{array}{l}180 \\
250 \\
260 \\
250\end{array}$ & $\begin{array}{l}200 \\
340 \\
350 \\
260\end{array}$ & $\begin{array}{l}220 \\
360 \\
370 \\
320\end{array}$ & $\begin{array}{l}250 \\
370 \\
400 \\
380\end{array}$ & $\begin{array}{l}300 \\
370 \\
380 \\
410\end{array}$ & $\begin{array}{l}-380 \\
370 \\
440\end{array}$ & $\begin{array}{l}\overline{380} \\
370 \\
430\end{array}$ \\
\hline & \multicolumn{3}{|c|}{ Average } & 235 & 288 & 318 & 350 & 365 & 397 & 393 \\
\hline \multirow[t]{2}{*}{60} & $\begin{array}{l}\text { F.S. } \\
\text { H. M. } \\
\text { W. H. } \\
\text { J. W. }\end{array}$ & & $\begin{array}{l}34 \\
26 \\
44 \\
54\end{array}$ & $\begin{array}{l}300 \\
220 \\
220 \\
220\end{array}$ & $\begin{array}{l}500 \\
420 \\
400 \\
450\end{array}$ & $\begin{array}{l}570 \\
550 \\
550 \\
640\end{array}$ & & & & \\
\hline & \multicolumn{3}{|c|}{ Average } & 240 & 442 & 578 & & & & \\
\hline
\end{tabular}




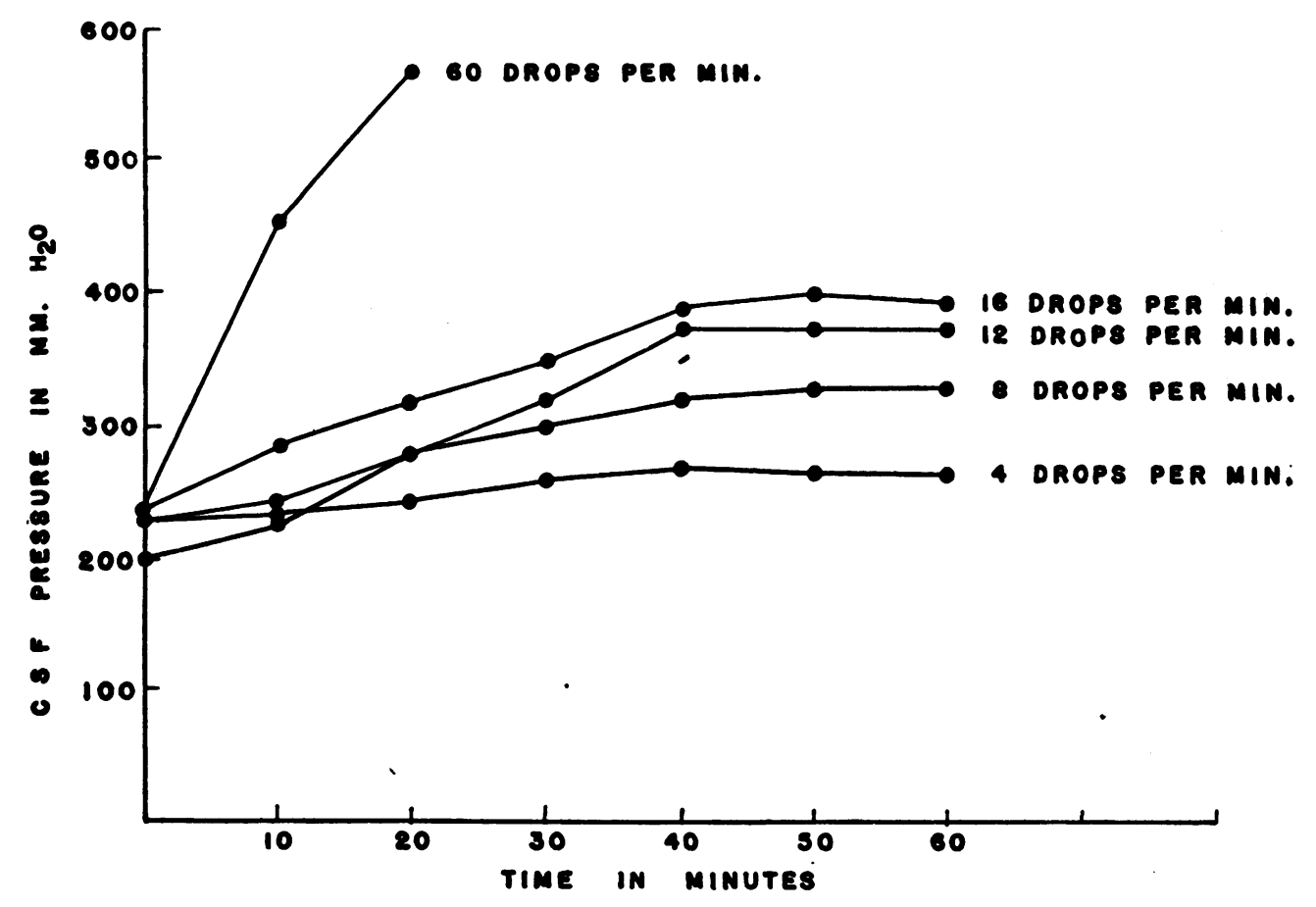

Fig. 2. Spinal Pressure Curves at Different Rates of Infusion

Each curve represents the mathematical average of four experiments.

minute at $360 \mathrm{~mm}$. pressure, with 16 drops per minute at $395 \mathrm{~mm}$. pressure.

When the subarachnoid infusion was administered at the rate of 60 drops per minute, the spinal fluid pressure rose rapidly and in 20 minutes it reached an average pressure of $570 \mathrm{~mm} . \mathrm{H}_{2} \mathrm{O}$. The infusion was discontinued at this point because of the possible dangers of further increase in pressure. Immediately after the infusion was discontinued, the spinal fluid pressure was followed closely. These observations were recorded in Figure 3, which represents the combined spinal fluid curves of four patients during and after the subarachnoid infusion of normal saline at the rate of 60 drops per minute. It can be seen that the cessation of the infusion was followed by a sharp drop in the spinal fluid pressure. Within four minutes the pressure decreased from $580 \mathrm{~mm} . \mathrm{H}_{2} \mathrm{O}$ to $350 \mathrm{~mm}$. of $\mathrm{H}_{2} \mathrm{O}$. From this time on, the pressure decrease was more gradual and 20 minutes after the end of the infusion the average pressure decreased to $295 \mathrm{~mm} . \mathrm{H}_{2} \mathrm{O}$. In the last ten minutes of the observation period the spinal fluid pressure remained practically unchanged. At this point the removal of 4 to $10 \mathrm{cc}$. of spinal fluid at the rate of $2 \mathrm{cc}$. per minute returned the pressure to normal.

Following the infusions at rates of $4,8,12$, and 16 drops per minute, the pressure was similarly increased to high levels at the end of the one-hour observation period, by the rapid infusion of saline over periods of ten to 20 minutes. After infusion was stopped the spinal fluid pressure decreased rapidly during the first four to five minutes, then the decrease became more gradual. Removal of 4 to $24 \mathrm{cc}$. of spinal fluid, at the rate of $2 \mathrm{cc}$. per minute, started at four to ten minutes after the end of the infusion, returned the spinal fluid pressures to near normal values.

Neurological observations carried out on a few of the first cases revealed no significant findings. Neither were any remarkable changes observed in pulse rate, respiration or blood pressure. Mild symptoms were observed in nine out of the 20 cases, and more marked symptoms developed in one patient. The symptoms developed in most cases when, at the end of the one-hour observation period, the rate of infusion was markedly increased. The most frequent complaints were tired feeling, numbness, tingling and dull pain in the 
legs, gluteal region or low back; in two cases similar symptoms were observed in the arms. Mild headache developed in two cases. In none of these nine cases were the symptoms severe enough to make necessary the premature termination of the infusion. All symptoms disappeared promptly when the infusion was discontinued or a few cubic centimeters of spinal fluid were removed. The only exception was patient A. S. who, after an uneventful observation period of one hour and a half, developed pain in the legs and arms when the rate of infusion was increased to 80 drops per minute. The patient suddenly became panicky, dyspneic, and the pulse rate jumped from 76 to 144 . The spinal needle became dislodged and it was impossible to replace it because of the patient's restlessness. Eleven mgs. of morphine were administered intravenously and after the patient quieted down the needle was reintroduced and $30 \mathrm{cc}$. of fluid were removed. The spinal fluid pressure returned to normal level and symptoms were relieved.

No after-effects (headache, backache, etc.) occurred in any of the 20 patients.

\section{COMMENTS}

The mechanism of the spinal fluid dynamics cannot as yet be considered clarified in every respect. It might not be superfluous to consider briefly some of the prevalent views on this subject before attempting to interpret our experimental findings.

It is generally accepted, that most of the cerebrospinal fluid is produced by the choroid plexuses of the lateral ventricles (3). Opinions differ as to whether the production of the cerebrospinal fluid is a secretion (4), or a filtration process (5). The cerebrospinal fluid produced in the lateral ventricles flows through the ventricles and reaches the outer surface of the medulla oblongata through the foramina Luschka. The existence of the foramen Magendi is doubtful in man (6). From here, most of the cerebrospinal fluid flows forward into the cisterna basalis and then into the subarachnoid space overlying the hemispheres. Thence a smaller portion flows into the cisterna magna and on into the spinal subarachnoid space. The absorption of the cerebrospinal fluid occurs through the arachnoid villi (Pacchionian bodies) projecting into the venous sinuses of the dura.

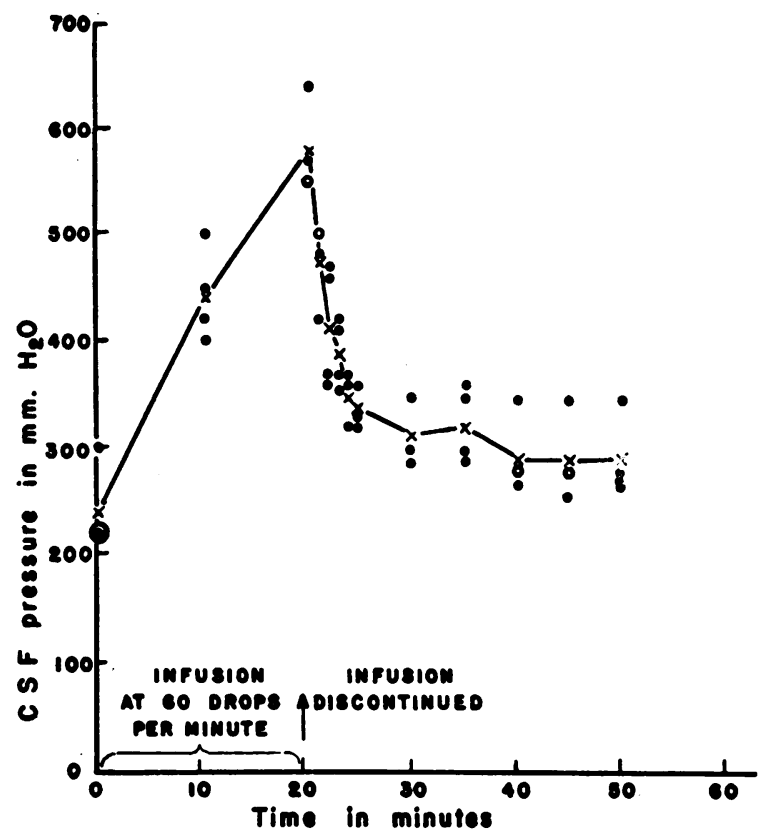

Fig. 3. Combined Spinal Fluid Curves of Four Patients During and After the Subarachnoid INfusion of Normal Saline, at the Rate of 60 Drops Per Minute

According to Weed (7) the absorption is due to the hydrostatic pressure of the cerebrospinal fluid (15-33 mm. $\mathrm{H}_{2} \mathrm{O}$ ) and to the osmotic pressure difference between the cerebrospinal fluid and the blood ( 250 to $300 \mathrm{~mm} . \mathrm{H}_{2} \mathrm{O}$ ). Normal pressure is due to an equilibrium between production and absorption (O'Connell) (3). Dandy and Blackfan (8) stated that normally 500 to $800 \mathrm{cc}$. of cerebrospinal fluid is produced daily and according to Masserman (1934) (9) if a small quantity of spinal fluid is removed it is replaced at the rate of $0.3 \mathrm{cc}$. per minute. Weed (10) found that the higher the injection pressure the more rapid the rate of absorption of normal saline from the subarachnoid space. The rate of absorption in dogs showed a linear relationship to pressure in the lower pressure ranges. With higher pressures the rate increased out of proportion. No difference was found between the rate of absorption of distilled water, Locke, and double Locke solutions (Mortensen and Weed) (11).

The dural sac of man can be considered as a fairly, but not absolutely rigid tube (Weed) (12). Consequently if fluid is administered intrathecally dilatation of the subarachnoid space can only com- 
pensate for the increased volume to a limited extent. Other possibilities of compensation are the increased rate of absorption through the arachnoid villi and displacement of blood (mostly venous) from the cerebrospinal circulation. Masserman and Schaller (13) found that in cadavers relatively sudden and large variations in cerebrospinal fluid pressure were fairly well transmitted from one part of the system to the other. There is no reason to believe that this should be different in the living.

The finding that at the infusion rate of 4 to 16 drops $(0.2 \mathrm{cc}$. to $0.8 \mathrm{cc}$.) per minute the pressure only rose to a certain point, at which point an equilibrium developed between the amount of fluid infused and absorbed, is in agreement with the data of Weed (10). Our results also indicate that, as was pointed out by Weed (10), the relationship between cerebrospinal fluid pressure and absorption is not linear. The increase in the rate of absorption as measured by the rise in spinal fluid pressure was relatively large at first, then became smaller, then again larger and finally smaller again as the infusion rate increased from 4 drops per minute to 60 drops per minute. The changes that occur in the cerebrospinal fluid dynamics while the infusion rate is increased from 4 to 60 drops per minute could perhaps be imagined in the following way: when the rate of infusion was 4 to 16 drops per minute, the relatively small quantities infused into the subarachnoid space were easily disposed of-probably by an increased rate of absorption alone. When the infusion rate was increased to 60 drops per minute, the elevation of the spinal fluid pressure could not establish an equilibrium between infusion and resorption at clinically safe pressure levels. This indicates that in this case the cerebrospinal fluid dynamics had to resort to other factors to compensate for the increased amount of cerebrospinal fluid. Since the brain is practically incompressible, the only other two possibilities for compensation were the expansion of the dural sac and the expression of blood from the vessels (mostly dural sinuses) of the central system. The elasticity of the dura is very low, hence expression of blood had to be the dominant factor. The shape of the spinal fluid pressure curve after the cessation of the infusion at the rate of 60 drops per minute seems to corroborate this assumption. The rapid fall in pressure in the first few minutes apparently corresponds to the absorption of that part of the cerebrospinal fluid that was present at the expense of the blood expressed from the vessels of the central nervous system and because of the possible distension of the dura. It might be assumed that from that point there are no gross changes in the volume of the vessels or in the distension of the dural sac, the decrease of the cerebrospinal fluid pressure progresses more slowly, and the pressure seems to be stabilized around $300 \mathrm{~mm} . \mathrm{H}_{2} \mathrm{O}$.

Seiro (14) in a somewhat different experimental setup measured the amount of fluid that could be infused into the subarachnoidal space in a given time (three or five minutes) at $400 \mathrm{~mm}$. $\mathrm{H}_{2} \mathrm{O}$ pressure. $\mathrm{He}$ also found that after stopping the infusion, the spinal fluid pressure dropped rapidly ( $150 \mathrm{~mm}$. in 2 to $3 \mathrm{~min}$.) at first and then more slowly.

Both Seiro (14) and Wolff and his associates (15) found very little or no clinical signs and symptoms that could be attributed to the elevation of the cerebrospinal fluid pressure. In one case where a cerebrospinal fluid pressure of $510 \mathrm{~mm}$. of $\mathrm{H}_{2} \mathrm{O}$ was maintained for ten minutes some discomfort was felt by the patient in the sacral region. In contrast to this, decrease of the spinal fluid pressure due to removal of fluid caused severe headache.

The method of study described in this paper might prove to be a useful tool in further studies of the dynamics of the cerebrospinal fluid. By changing the chemical composition of the fluid administered in the subarachnoid space it might be possible to find out whether or not the resorption of the cerebrospinal fluid is a filtration process. The selective absorption or retention of certain substances would indicate that other biological factors also have a part in resorption. It might also be possible to utilize the method as a neurological diagnostic procedure that would give quantitative information as to the changes of absorption of the cerebrospinal fluid in various pathological conditions.

\section{SUMMARY}

1. Normal saline was administered intrathecally at the rates of 4 to 60 drops $(0.2$ to $3 \mathrm{cc}$.) per minute. 
2. When the rate of infusion was between 4 and 16 drops per minute, an equilibrium developed between the elevated cerebrospinal fluid pressure and the rate of absorption of the cerebrospinal fluid. The equilibrium was reached at progressively higher levels as the rate of infusion was increased. The relationship between rate of absorption and pressure is not linear.

3. No equilibrium was obtained within clinically safe pressure limits when the rate of infusion was 60 drops per minute.

4. After the infusion was discontinued the spinal fluid pressure decreased at first rapidly (180 mm. of $\mathrm{H}_{2} \mathrm{O}$ in four minutes), then more slowly.

5. The elevation of the cerebrospinal fluid pressure to between 500 and $600 \mathrm{~mm}$. of $\mathrm{H}_{2} \mathrm{O}$ for ten to 20 minutes produced mild symptoms in about half of the patients. No untoward after effects were observed in any of the 20 patients.

\section{BIBLIOGRAPHY}

1. Arrowood, J. G., and Foldes, F. F., Continuous drop method for subarachnoid analgesia: preliminary report. Anesthesiology, 1944, 5, 465.

2. Arrowood, J. G., and Foldes, F. F., Subarachnoid analgesia maintained by the continuous drop method. Arch. Surg., 1944, 49, 241.

3. O'Connell, J. E. A., The vascular factor in intracranial pressure and the maintenance of cerebrospinal fluid circulation. Brain, 1943, 66, 204.
4. Flexner, L. B., Some problems of origin, circulation, and absorption of cerebrospinal fluid. Quart. Rev. Biol., 1933, 8, 397.

5. Fremont-Smith, F., Nature of cerebrospinal fluid. Arch. Neurol. and Psychiat., 1927, 17, 317.

6. Merritt, H. H., and Fremont-Smith, F., The Cerebrospinal Fluid. W. B. Saunders \& Co., Philadelphia, 1938.

7. Weed, L. H., Certain anatomical and physiological aspects of meninges and cerebrospinal fluid. Brain, $1935,58,387-397$.

8. Dandy, W. E., and Blackfan, K., Internal hydrocephalus, an experimental, clinical and pathological study. Am. J. Dis. Child., 1914, 8, 406.

9. Masserman, J. H., Cerebrospinal hydrodynamics, IV. Clinical experimental studies. Arch. Neurol. and Psychiat., 1934, 32, 523.

10. Weed, L. H., Forces concerned in the absorption of cerebrospinal fluid. Am. J. Physiol., 1935, 114, 40.

11. Mortensen, O. A., and Weed, L. H., Absorption of isotonic fluids from subarachnoid space. Am. J. Physiol., 1934, 108, 458.

12. Weed, L. H., Some limitations of Munroe-Kellie hypothesis. Arch. Surg., 1929, 18, 1049.

13. Masserman, J. H., and Schaller, W. F., Intracranial hydrodynamics: experiments on human cadavers. Arch. Neurol. and Psychiat., 1933, 29, 1222.

14. Seiro, V., Utber die Messung des intraduralen Reserveraums. Acta. Chir. Scandinav., 1943, 89, 139.

15. Kunkle, E. C., Ray, B. S., and Wolff, H. G., Experimental studies on headache; analysis of the headache associated with changes in intracranial pressure. Arch. Neurol. and Psychiat., 1943, 49, 323. 